\title{
Plasmodium infection and its risk factors in eastern Uganda
}

Rachel L Pullan ${ }^{1 *}$, Hasifa Bukirwa ${ }^{2}$, Sarah G Staedke ${ }^{1,2}$, Robert W Snow ${ }^{3,4}$, Simon Brooker ${ }^{1,3}$

\begin{abstract}
Background: Malaria is a leading cause of disease burden in Uganda, although surprisingly few contemporary, age-stratified data exist on malaria epidemiology in the country. This report presents results from a total population survey of malaria infection and intervention coverage in a rural area of eastern Uganda, with a specific focus on how risk factors differ between demographic groups in this population.

Methods: In 2008, a cross-sectional survey was conducted in four contiguous villages in Mulanda, sub-county in Tororo district, eastern Uganda, to investigate the epidemiology and risk factors of Plasmodium species infection. All permanent residents were invited to participate, with blood smears collected from 1,844 individuals aged between six months and 88 years (representing $78 \%$ of the population). Demographic, household and socioeconomic characteristics were combined with environmental data using a Geographical Information System. Hierarchical models were used to explore patterns of malaria infection and identify individual, household and environmental risk factors.
\end{abstract}

Results: Overall, 709 individuals were infected with Plasmodium, with prevalence highest among 5-9 year olds (63.5\%). Thin films from a random sample of $20 \%$ of parasite positive participants showed that $94.0 \%$ of infections were Plasmodium falciparum and 6.0\% were P. malariae; no other species or mixed infections were seen. In total, $68 \%$ of households owned at least one mosquito although only $27 \%$ of school-aged children reported sleeping under a net the previous night. In multivariate analysis, infection risk was highest amongst children aged 5-9 years and remained high in older children. Risk of infection was lower for those that reported sleeping under a bed net the previous night and living more than $750 \mathrm{~m}$ from a rice-growing area. After accounting for clustering within compounds, there was no evidence for an association between infection prevalence and socio-economic status, and no evidence for spatial clustering.

Conclusion: These findings demonstrate that mosquito net usage remains inadequate and is strongly associated with risk of malaria among school-aged children. Infection risk amongst adults is influenced by proximity to potential mosquito breeding grounds. Taken together, these findings emphasize the importance of increasing net coverage, especially among school-aged children.

\section{Background}

In Uganda, malaria remains the leading cause of morbidity and mortality, with an estimated 12 million clinical cases treated annually in the public health system alone [1]. To address this burden, the principal intervention strategies currently implemented include the use of insecticide-treated nets (ITNs) and long-lasting insecticide nets (LLINs), prompt effective treatment with artemisinin-based combination therapy (ACT), indoor

\footnotetext{
* Correspondence: rachel.pullan@lshtm.ac.uk
'Department of Infectious and Tropical Diseases, London School of Hygiene

* Correspondence: rachel.pullan@lshtm.ac.uk
'Department of Infectious and Tropical Diseases, London School of Hygiene and Tropical Medicine, UK
}

(C) 2010 Pullan et al; licensee BioMed Central Ltd. This is an Open Access article distributed under the terms of the Creative Commons Attribution License (http://creativecommons.org/licenses/by/2.0), which permits unrestricted use, distribution, and reproduction in any medium, provided the original work is properly cited. prevention in pregnant women. As approaches to malaria control evolve there is a continuing requirement to understand the epidemiology and determinants of malaria infection risk under varying levels of parasite transmission intensity. This is best achieved through comprehensive, community-based studies. However, consistent with a focus on the epidemiology of severe malaria morbidity [2,3], most recent studies in Uganda have been hospital-based, investigating clinical malaria among young children and pregnant women [4-7]. This report presents results from a community-based study aimed at 
defining the demographic and epidemiological patterns of malaria parasitaemia and to determine micro-geographic and socio-economic factors that influence the risk of infection among a community in Eastern Uganda.

\section{Methods}

\section{Description of the study site}

The study was conducted in four villages in Mulanda sub-county, located in Tororo district, eastern Uganda in 2008. The area is characterized by dry savannah grassland interrupted by bare rocky outcrops and lower lying swamps, although natural vegetation has mostly been replaced by cultivated crops. Average daytime temperature is $27^{\circ} \mathrm{C}$, with two rainy seasons (March to May and August to October); annual rainfall is 1,000-1,500 $\mathrm{mm}^{2}$. The sub-county was purposively chosen as having a large population, being accessible to a health centre IV and as being representative of an area of high (stable) malaria transmission [8]. Most malaria is caused by Plasmodium falciparum. A 1999 survey among 1-9 year olds in Nagongera, $15 \mathrm{~km}$ away from Mulanda, reported a P. falciparum prevalence of $90.6 \%$ [9]. Estimates of entomological inoculation rates suggest that individuals receive on average 562 infective $P$. falciparum bites per year [10]. The major vector species in the region has been shown to be Anopheles gambiae s.s., and to a lesser extent Anopheles funestus [10]. No vector control activities had been undertaken in the sub-country either before or during the study. Routine malaria control in the district is typically limited to the promotion of intermittent preventive treatment during pregnancy and the distribution of insecticide-treated nets through antenatal care services; however, until now these government initiatives have had limited success [11], and no additional schemes (such as community-based mosquito net distribution campaigns) were implemented in the two years prior to this investigation.

\section{Census, demographic survey and mapping}

Between July and December 2008, a complete census and household survey of the entire sub-county was conducted by the study team in order to gather basic demographic and socio-economic information about the target population. Study personnel systematically covered the subcounty on foot to identify and enumerate all households, and invite an adult resident (18 years of age and older) from each household to participate in a brief socio-demographic survey. Using a standardized questionnaire, information was gathered on the age and gender of each resident and socio-economic characteristics including house construction, water and sanitation, and ownership of selected household assets. A resident was defined as a person who intended to sleep primarily at that location for the subsequent six months. In total, 33,167 individuals residing in 6,397 households were enumerated in the sub-county.
Household locations were mapped using a hand-held eTrex global positioning system (GPS) receiver (Garmin Ltd., Olathe, KS). All health care facilities (public and private clinics, drugs vendors and pharmacies), open and protected water sources and other points of interest (schools, trading centres) were also geo-located using a GPS. High resolution $(0.6 \mathrm{~m})$ QuickBird satellite data were obtained (dated October 16, 2003) and used for geo-referencing the location of roads, infrastructure and potential mosquito breeding sites. Geographic data were compiled and maps created using ArcGIS 9.2 (Environmental Systems Research Institute Inc., Redlands, CA, USA). Nearest straight-line distances between residents' compounds and the health centre and potential mosquito breeding sites were calculated in ArcGIS.

\section{Recruitment and enrolment}

For inclusion in the present study (a total population biomedical survey describing demographic and epidemiological patterns of malaria parasitaemia within the sub-county) four villages covering an area of $7.5 \mathrm{~km}^{2}$ surrounding the health centre IV were selected as geographically and socio-economically representative of the sub-county, with easy accessibility and moderate population density (Figure 1). No population weighting was used in the sampling. From September to December 2008 - which corresponds to the (later than expected) rainy season - home visitors approached all enumerated households in the four study villages to provide a brief description of the study, and to invite residents to attend an appointment at a mobile health post established for the study. Residents not at home or failing to attend their appointment were revisited up to three times over the next two weeks to assess interest in the study. Upon attending the health post, only those residents that could be unambiguously tied to a single household, resident in the study site over the last 24 months, did not work full time or attend school outside the sub-county, and were willing to give informed consent were enrolled into the study. However, excluded individuals were still offered parasitological examinations and treatment, but were not considered part of the data set for analysis.

\section{Study procedures}

Upon enrolment a questionnaire was administered to adults and to mothers (or carers) of children to record demographic and socio-economic characteristics, medical history and mosquito net use. A clinical examination was then performed that included axillary temperature (measured using a digital thermometer) and height and weight. A rapid diagnostic test for malaria (OptiMAL; DiaMed, Cressier, Switzerland) was performed on all participants with fever (temperature $>37.2^{\circ} \mathrm{C}$ ) or reported history of fever in the previous 24 hours. Those with a positive test but no evidence of severe 


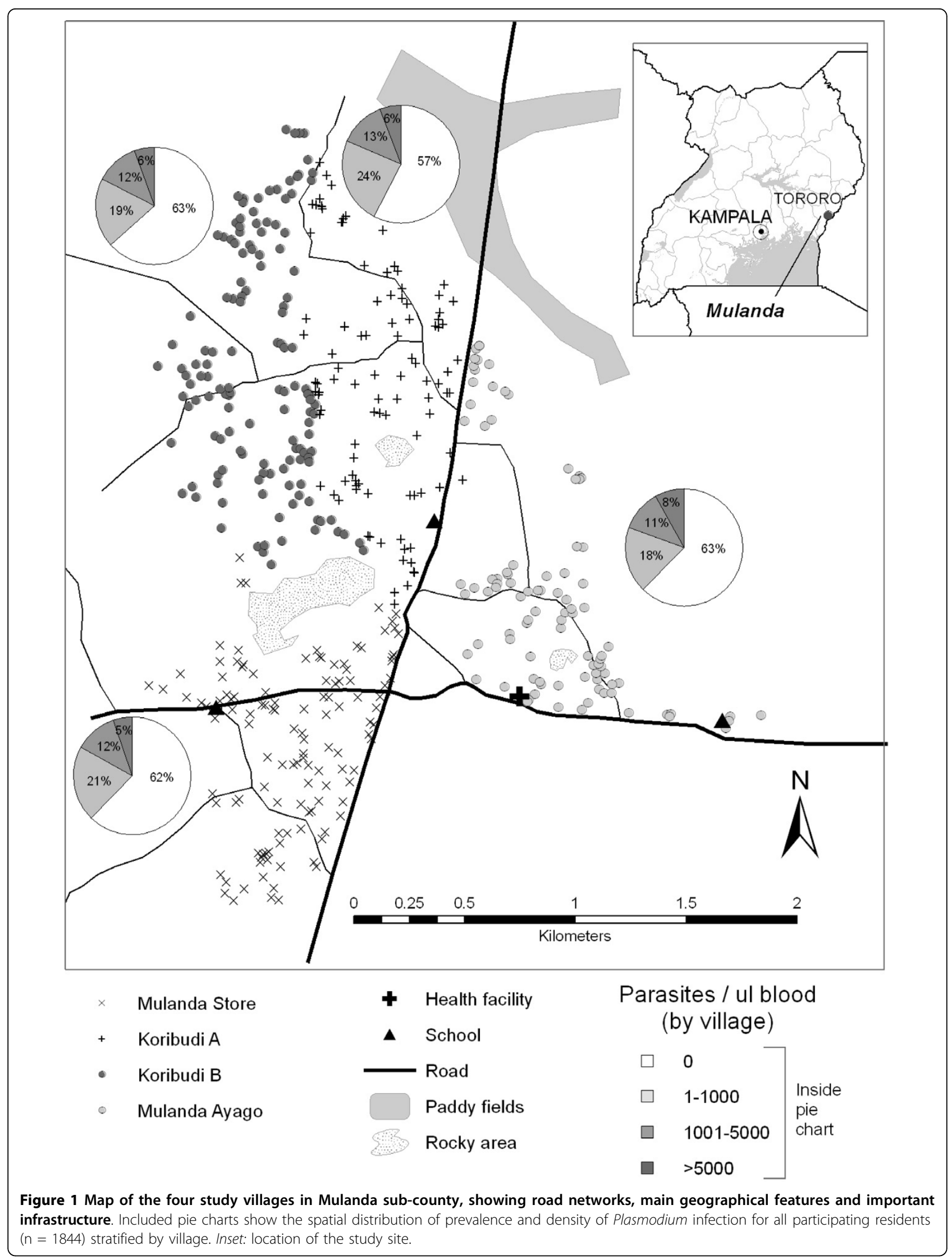


illness were diagnosed with uncomplicated malaria and treated with a 6-dose regimen of co-artemether (Coartem, Novartis, $20 \mathrm{mg}$ artemether/120 mg lumefantrine) in accordance with national guidelines. Research participants found by the study nurses to be suffering from severe malaria or an illness not covered by the protocol were referred to the local health facility (a county-level referral facility) for diagnosis and management as recommended by national guidelines. Finger-prick (or heal-prick from infants) blood samples were obtained to assess haemoglobin using a portable photometer (Hemocue, Angelholm, Sweden) and to prepare thin and thick blood films. Individuals were also asked to provide stool samples which were examined microscopically for the eggs of intestinal nematodes and Schistosoma mansoni, using the Kato-Katz technique.

Blood slides prepared for malaria were declared negative only after examination of 100 high-powered fields by two independent microscopists. Thin films from a sub-sample of $20 \%$ of parasite positive participants were read for species identification showing that $94.0 \%$ were P. falciparum and $6.0 \%$ were P. malariae; no other species or mixed infections were seen.

\section{Statistical analysis}

All data were double-entered and cross-checked using Access (Microsoft). Statistical analyses were carried out using Stata XI software (Stata Corporation, College Station, Texas) and WinBUGs version 1.4.1 (Imperial College and Medical Research Council, London, UK). Two outcome variables were initially analysed: i) the prevalence of Plasmodium infection, and ii) Plasmodium parasite density in positive participants. However, analysis of parasite density revealed no additional insights and therefore the focus of the present analysis is on infection prevalence.

Information on ownership of household assets was used to construct a wealth index for each household using principal component analysis (PCA), using the method of Filmer and Pritchett [12]. Variables entered into the PCA included ownership of mobile phones, radios, factory-made mattresses, electric irons, motor bikes, bicycles and cattle. The first principle component explained $23.4 \%$ of the overall variability in the included variables and gave greatest weight respectively to ownership of a mobile phone (0.37), followed by radio $(0.36)$, factory-made mattress (0.35) and watch or clock (0.35); the lowest weight was given to ownership of none of the listed items (-0.39). The resulting score was divided into quintiles, to provide a categorical measure of relative socio-economic status. Household factors potentially directly associated with infection outcomes, including toilet facilities and household construction materials, were not included in the wealth index to allow for independent assessment of their contribution.
Pearson's chi-squared test and Fisher's test were used to compare proportions between groups as appropriate. Potential risk factors for prevalence were initially investigated using frequentist logistic regression models. Explanatory variables significant at the $10 \%$ significance level were subsequently entered into a Bayesian multivariate logistic regression model, using a process of backwards-stepwise elimination. Between-household variation was taken into account by introducing into the model household-level random effects with an exchangeable correlation structure. Analysis employed a Bayesian Monte Carlo Markov Chain (MCMC) approach, which readily allows the development of random effects models [13]. Inference was based on the better fitting model, which was selected using the deviance information criteria (DIC) as a goodness of fit measure. Analysis was stratified into three age groups in order to investigate risk factors by demographic groups: pre-school children ( $<5$ years), school-aged children (515 years) and adults ( $\geq 16$ years).

In order to assess global spatial heterogeneity in infection patterns across the whole study site, semi-variograms were generated using the $\mathrm{R}$ module GeoR. Monte Carlo envelopes (computed from random permutations of the residuals from random permutations of the data holding the corresponding locations fixed) were used to formally assess whether the data was compatible with spatial structure, under the assumption of no correlation $[14,15]$. Semi-variograms were also computed for households aggregated to the closest $100 \mathrm{~m}, 150 \mathrm{~m}$ and $200 \mathrm{~m}$ to overcome the problem of a small denominator in households with few residents. Variography was repeated for the random effects of the fitted Bayesian multivariate models to order assess residual spatial correlation once explanatory variables had been taken into account.

\section{Ethics}

The study protocol was approved by the Makerere University Faculty of Medicine Research and Ethics Committee (\#2008-043) Uganda National Council of Science and Technology (\#HS 476) and London School of Hygiene and Tropical Medicine Ethics Committee (\#5261). Prior to the start of the study, investigators met with elected government representatives and community leaders to inform them of the study and explain the methodology. Verbal consent was obtained for the brief census survey described above. Written informed consent was obtained from all adults and from parents or guardians of minors for participation in the biomedical survey; written assent was also obtained for children aged 13-18 years.

\section{Results}

Of the 2,474 individuals from 491 households enumerated in census, 116 were no longer living in residence by time of the biomedical survey. A total of 2,358 
residents living in 473 households were invited to attend the health post; $2,037(86.4 \%)$ individuals chose to attend and could be unambiguously tied to a single household. Of these, 34 individuals were excluded from enrolment ( 16 because they had not been resident in the study area for the previous 24 months, and 18 because they were aged $<6$ months), 58 refused to provide a finger prick, 83 did not provide household socioeconomic data and 19 did not provide information on bed net usage. Complete questionnaire and biomedical data was, therefore, available for 1,844 individuals from 438 households $(78.2 \%$ of the total population). Individual and household characteristics for participants enrolled in the study are summarized in Table 1: comparison of census data for the individuals included in the final sample with those who chose not to participate indicates that the final study population under-sampled adult males $(\mathrm{p}<0.001)$. There were however no statistical difference in the relative socio-economic status of participant and non-participant households, nor of bed net ownership (Table 1).
Overall, $38.5 \%$ of individuals were infected with Plasmodium spp. Figure 1 shows the household distribution of presence and density of Plasmodium spp. parasitaemia stratified by village. Prevalence did not significantly vary between villages $\left(\chi^{2} 3.84 ; \mathrm{p}=0.3\right): 37.8 \%$ in Mulanda Store, $36.6 \%$ in Koribudi B, 37.8\% in Mulanda Ayago and $42.6 \%$ in Koribudi A. Examination of semivariograms for household prevalence found no evidence of consistent global spatial structure, indicating that on average across the whole study site infection was randomly distributed (data not shown). Prevalence was significantly higher among males than females $(43.3 \%$ versus $34.5 \%, \mathrm{p}<0.001)$ and peaked among individuals aged five to nine years (63.5\%), falling to $29.1 \%$ by 16 years and $12.9 \%$ in those over 30 years old (Figure 2).

The majority (67.9\%) of households owned at least one mosquito net; $45.1 \%$ of which were long lasting insecticide nets (LLIN) or had been treated with an insecticide (ITN). Net ownership increased with socioeconomic status, ranging from $43.2 \%$ any net $/ 17.2 \%$ ever-treated net among households of the poorest

Table 1 Comparison of census population for the study villages with that for entire sub-county, and enrolled households/participants with those that chose not to participate (refusals).

\begin{tabular}{|c|c|c|c|c|c|c|}
\hline $\begin{array}{l}\text { Household } \\
\text { Characteristics a }^{\text {a }}\end{array}$ & $\begin{array}{l}\text { Study villages } \\
(n=496)\end{array}$ & $\begin{array}{l}\text { Sub-county } \\
(n=6,397)\end{array}$ & $P^{\mathrm{d}}$ & $\begin{array}{l}\text { Participants } \\
(n=438)\end{array}$ & $\begin{array}{l}\text { Refusals } \\
(n=58)\end{array}$ & $P^{\mathrm{e}}$ \\
\hline $\begin{array}{l}\text { Residents: median } \\
\text { (range) }\end{array}$ & $5(1-15)$ & $5(1-15)$ & 0.99 & $5(1-10)$ & $3(1-14)$ & $<0.001$ \\
\hline \multicolumn{7}{|l|}{ Construction of home: } \\
\hline Mud and wattle & $78.2 \%$ & $72.8 \%$ & & $78.8 \%$ & $71.0 \%$ & \\
\hline Bricks & $12.2 \%$ & $16.5 \%$ & 0.0 & $11.9 \%$ & $19.4 \%$ & 0.25 \\
\hline Cement/concrete & $9.6 \%$ & $10.7 \%$ & & $9.4 \%$ & $9.7 \%$ & \\
\hline Own $\geq$ one bed net & $68.2 \%$ & $64.7 \%$ & 0.1 & $67.8 \%$ & $62.9 \%$ & 0.4 \\
\hline$\geq 1$ net per 2 residents & $20.3 \%$ & $16.3 \%$ & 0.1 & $18.1 \%$ & $33.9 \%$ & 0.005 \\
\hline Own $\geq$ asset $^{b}$ & $87.9 \%$ & $89.1 \%$ & 0.4 & $87.7 \%$ & $87.1 \%$ & 0.9 \\
\hline \multicolumn{7}{|c|}{ Socioeconomic group ${ }^{c}$} \\
\hline Poorest & $20.9 \%$ & $22.7 \%$ & & $20.1 \%$ & $20.3 \%$ & \\
\hline Poor & $21.8 \%$ & $19.6 \%$ & & $22.6 \%$ & $22.0 \%$ & \\
\hline Median & $18.7 \%$ & $15.0 \%$ & 0.0 & $18.5 \%$ & $11.7 \%$ & 0.7 \\
\hline Less poor & $19.3 \%$ & $18.4 \%$ & & $19.2 \%$ & $20.3 \%$ & \\
\hline Least poor & $19.3 \%$ & $24.3 \%$ & & $19.6 \%$ & $25.4 \%$ & \\
\hline $\begin{array}{l}\text { Individual } \\
\text { Characteristics a }\end{array}$ & $\begin{array}{l}\text { Study villages } \\
(\mathrm{n}=2358)\end{array}$ & $\begin{array}{l}\text { Sub-county } \\
(n=33,167)\end{array}$ & $P^{d}$ & $\begin{array}{l}\text { Participants } \\
(\mathrm{n}=1844)\end{array}$ & $\begin{array}{l}\text { Refusals } \\
(n=514)\end{array}$ & $P^{\mathrm{e}}$ \\
\hline Mean age in years (SD) & $21.8(21.1)$ & $20.2(20.0)$ & $<0.001$ & $21.3(21.0)$ & $22.6(20.4)$ & $<0.001$ \\
\hline \multicolumn{7}{|l|}{ Age group } \\
\hline Under 5 yrs & $19.2 \%$ & $19.6 \%$ & & $21.5 \%$ & $16.1 \%$ & \\
\hline School aged (5-15) & $34.1 \%$ & $36.0 \%$ & 0.06 & $34.9 \%$ & $29.4 \%$ & $<0.001$ \\
\hline Adults $(16+)$ & $46.8 \%$ & $44.4 \%$ & & $43.6 \%$ & $54.6 \%$ & \\
\hline Gender (\% male) & $49.2 \%$ & $48.3 \%$ & 0.3 & $45.2 \%$ & $57.2 \%$ & $<0.001$ \\
\hline
\end{tabular}

a Ascertained during household census

b assets include: iron, clock, factory-made mattress, bicycle, radio, television sofa, fridge, mobile phone, motorcycle and car

${ }^{c}$ groups defined by scores from the first component of PCA (asset ownership) performed on census data from the four study villages

d P-value: study village (all residents/households) vs. sub-county (all residents/households)

e P-value: study participants vs. those resident in the study villages who chose not to participate 
A

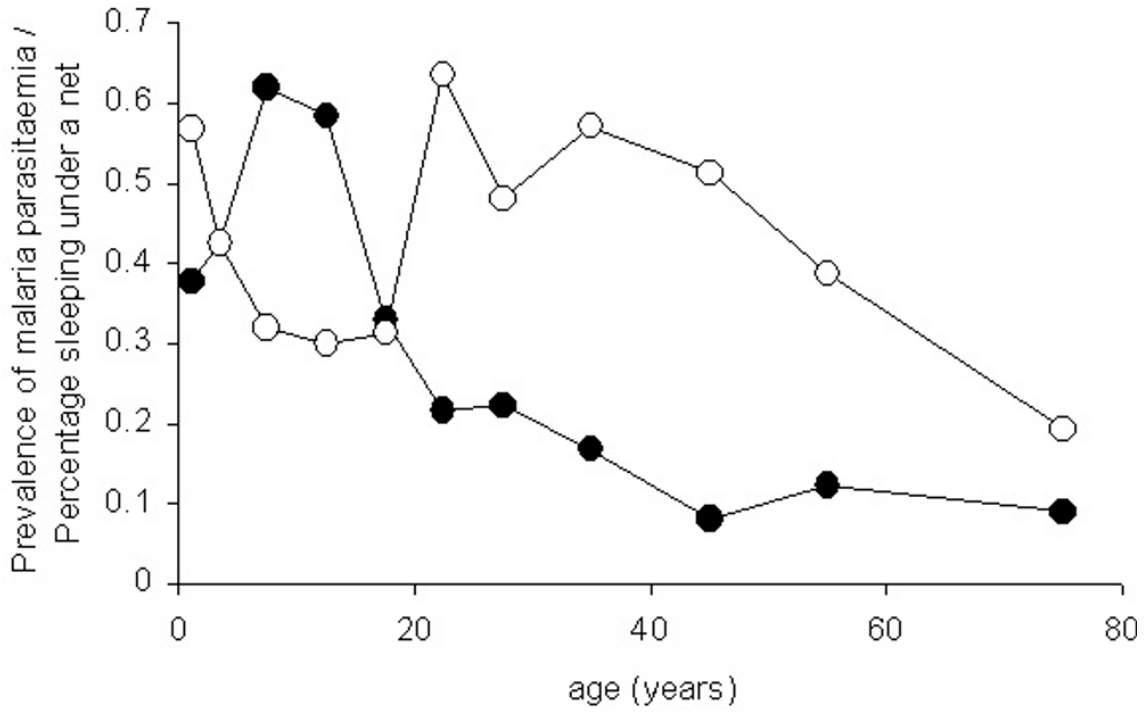

B

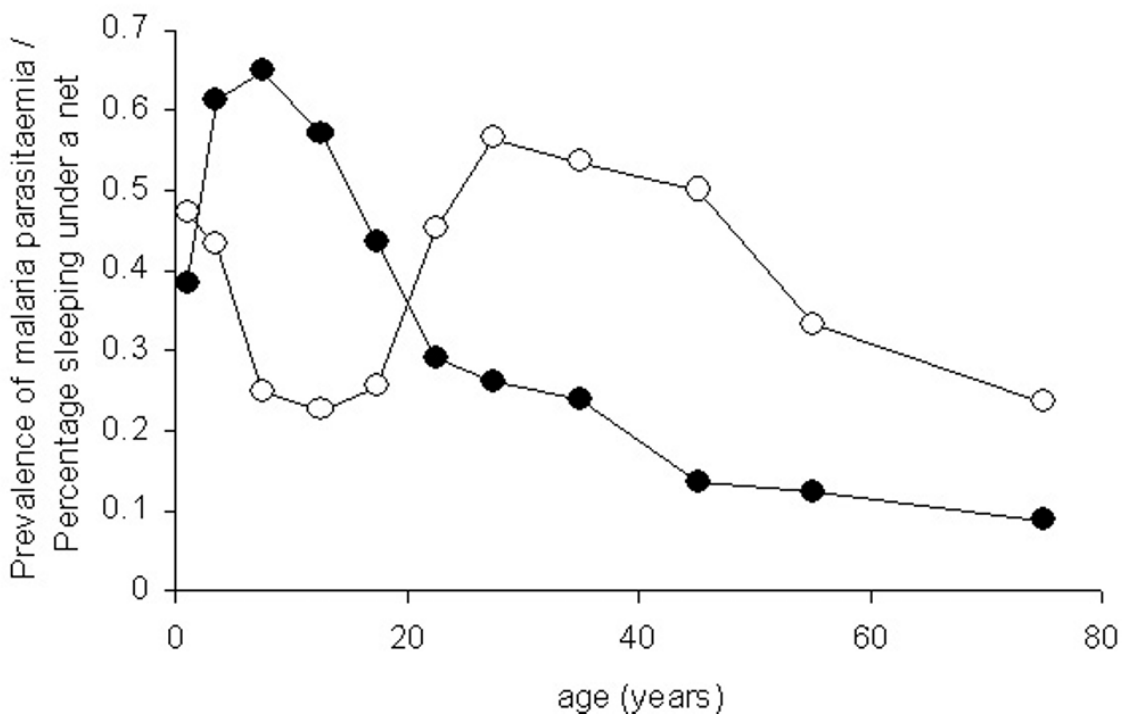

Figure 2 Age patterns in the prevalence malaria parasitaemia (solid circles) and percentage reporting sleeping under a bed net the previous night (open circles) for (A) females and (B) males.

quintile to $95.0 \%$ any net $/ 50.0 \%$ ever-treated net among the richest quintile $(\chi 2, \mathrm{p}<0.001)$. However, only $9.9 \%$ of households owned at least one net per two residents, the Uganda national recommended minimum net coverage, and only $39 \%$ of participants reported having slept under a bed net the previous night. In terms of differences by age, net use was initially highest among preschool children, sharply declining among school-aged children, before rising again across the ages 20-44 years and finally decreasing gradually in older ages; this pattern was similar among females and males (Figure 2). Reported usage in school-aged children was also strongly associated with education level of the household head and of the primary carer (both significant correlates of socio-economic status): for example, usage ranged from $17.4 \%$ among those whose primary carer had no formal education to $55.1 \%$ in those whose primary carer had attended secondary school ( $\mathrm{p}<0.001)$. 
Results of the univariate analysis of risk factors for Plasmodium infection are provided in Additional File 1, both overall and stratified by age group. Overall, sex and age were identified as significant risk factors, although sex was not significantly associated after stratifying by age group. Infection risk was significantly lower among pre-school children living in households in possession of an ever-treated net and with minimum adequate mosquito net coverage, and those reported to have slept under a mosquito net the previous night. Reported net usage was associated with decreased risk among schoolaged children, but not among adults. Across all age groups, living $>750 \mathrm{~m}$ from rice growing areas and open springs (both potential mosquito breeding areas) was associated with decreased risk, whilst living $>1,000 \mathrm{~m}$ from the health centre was associated with increased risk. Notably, relative socio-economic status was not associated with infection risk among any age group.

The results of the Bayesian multivariate random-effect logistic regression are shown in Table 2. The risk of infection was significantly reduced for those individuals reporting sleeping under a net the previous night and living $>750 \mathrm{~m}$ from rice fields. When stratified by age group, infection risk was significantly decreased among pre-school children living in a household in possession of an ever-treated net or with minimum adequate net coverage, and among school-aged children who reported sleeping under a net the previous night. Risk in adults was defined by location of their household of residence: reduced risk among those living $>750 \mathrm{~m}$ from rice fields and increased risk among those living $>1,000 \mathrm{~m}$ from the health centre. Comparison of DIC values revealed that clustering within compounds appreciably improved the fit of all models, suggesting that after adjusting for bed net usage and location of the household, there was strong statistical evidence of household clustering of infection; this clustering was independent of the spatial location of households.

\section{Discussion}

Community-based epidemiological studies serve an important public health role since they provide contemporary estimates of infection prevalence and intervention coverage, and can identify factors whose manipulation could further prevent or control malaria in endemic populations. In Uganda, there are remarkable few recent studies of malaria within communities, with previous detailed descriptions provided by Onori

Table 2 Bayesian multivariate analysis of the prevalence of Plasmodium spp. parasitaemia, overall and stratified by age group

\begin{tabular}{|c|c|c|c|c|c|c|c|c|}
\hline \multirow[b]{3}{*}{ Parameter: } & \multicolumn{2}{|c|}{ All ages } & \multicolumn{2}{|c|}{ Pre-school } & \multicolumn{2}{|c|}{ School-aged } & \multicolumn{2}{|c|}{ Adults } \\
\hline & \multicolumn{2}{|c|}{ (0-85 years) } & \multicolumn{2}{|c|}{ (<5 years) } & \multicolumn{2}{|c|}{ (5-15 years) } & \multicolumn{2}{|c|}{ ( $\geq 16$ years) } \\
\hline & OR & $(95 \% \mathrm{BCl})$ & OR & $(95 \% \mathrm{BCl})$ & OR & $(95 \% \mathrm{BCl})$ & OR & $(95 \% \mathrm{BCl})$ \\
\hline \multicolumn{9}{|c|}{ Personal characteristics: } \\
\hline \multicolumn{9}{|l|}{ Age (in years): } \\
\hline$<2$ & 1 & & 1 & & - & & - & \\
\hline $3-4$ & 1.78 & $(1.16-2.74)$ & 2.06 & $(1.22-3.56)$ & - & & - & \\
\hline $5-9$ & 3.01 & $(2.02-4.45)$ & - & & - & & - & \\
\hline $10-15$ & 2.15 & $(1.46-3.23)$ & - & & - & & - & \\
\hline $16-25$ & 0.59 & $(0.19-0.45)$ & - & & - & & 1 & \\
\hline $26-49$ & 0.29 & $(0.08-0.25)$ & - & & - & & 0.50 & $(0.31-0.78)$ \\
\hline $50+$ & 0.14 & $(0.19-0.45)$ & - & & - & & 0.27 & $(0.15-0.48)$ \\
\hline Age-linear term & - & & - & & 0.94 & $(0.89-0.99)$ & - & \\
\hline \multicolumn{9}{|c|}{ Household characteristics: } \\
\hline $\begin{array}{l}\text { Slept under a } \\
\text { net last night? }\end{array}$ & 0.75 & $(0.58-0.96)$ & - & & 0.57 & $(0.38-0.86)$ & - & \\
\hline $\begin{array}{l}\geq 1 \text { net per } 2 \\
\text { residents }\end{array}$ & - & & 0.15 & $(0.02-0.72)$ & - & & - & \\
\hline $\begin{array}{l}\text { LLIN/ITN in } \\
\text { household }^{\text {a }}\end{array}$ & - & & 0.47 & $(0.23-0.89)$ & - & & - & \\
\hline $\begin{array}{l}\text { Rice growing } \\
\text { area }>750 \mathrm{~m}\end{array}$ & 0.65 & $(0.47-0.89)$ & - & & - & & 0.49 & $(0.28-0.82)$ \\
\hline $\begin{array}{l}\text { Health centre } \\
>1000 \mathrm{~m}\end{array}$ & - & & - & & - & & 1.75 & $(1.02-3.06)$ \\
\hline \multicolumn{9}{|c|}{ Variance parameter: } \\
\hline Household $\sigma^{2}$ & 0.45 & $(0.20-0.76)$ & 2.02 & $(0.23-4.75)$ & 0.44 & $(0.04-1.14)$ & 0.51 & $(0.03-1.44)$ \\
\hline
\end{tabular}

Parameters left blank were omitted in the final multivariate model for this demographic model.

${ }^{\text {a }}$ LLIN long-lasting insecticidal net; ITN insecticide-treated net 
and Jelliffe in the 1960s [16-20] and sentinel site studies by Okello and Talisuna from 1999-2006 [9,10,21]. The results from the present study show that in eastern Uganda $P$. falciparum infection remains highly prevalent (38.5\%), although prevalence in children aged 1-9 years is lower than that reported in 1999 by Talisunu et al for the same age group in a neighbouring population $(55.0 \%$ vs. 90.6\%) [9]. Mosquito net ownership remains unacceptably low, with only $31 \%$ of households owning at least one ever-treated mosquito net (ITN or LLIN). Whilst this is higher than the 2006 Uganda regional average (24\%) [11], it is still considerably lower than the government Malaria Control Programme's stated aim of $85 \%$ by 2010 . Nonetheless, these results show that sleeping under a net is strongly associated with a decreased risk of infection, especially among school-aged children.

Mosquito net use was found to be lowest among school-aged children, an observation also reported during individual studies in Tanzania [22-24], South Central Somalia [25], Ethiopia [26] and Nigeria [27], and in an analysis of data from 18 national household surveys [28]. Although data were not explicitly collected on where participants acquired their bed nets, such variation by age group may be the consequence of net distribution programmes that have historically focused on providing nets to young children and pregnant women during routine clinic visits or mass-catch-up immunization campaigns. The findings may additionally be explained by household sleeping patterns with schoolaged children sleeping together on separate beds from young children and their mothers. Those school-aged children who did report sleeping under a net were at nearly half the risk of malaria infection compared to those that did not. In contrast, net use was not associated with infection risk among adults, who presumably remain outside until later in the evening, increasing their likelihood of being bitten. Previous estimates of the protection afforded by mosquito nets vary widely across different settings, with cross-sectional studies providing evidence of higher protective efficacy (51-63\%) $[25,29,30]$ than estimates from randomized controlled trials (13-15\%) [31]. While differences in study design and transmission settings make comparisons between studies difficult, our finding that mosquito nets offer high rates of protection in school-aged children are consistent with individual cross-sectional studies in Somalia [25] and Tanzania [32].

Notable among the results was a lack of association between infection risk and socio-economic factors. This contrasts with previous studies conducted in both rural and peri-urban settings that have reported increased risk of malaria infection in children living in poor housing [33,34] and with low socio-economic status [35-37]. The observed lack of association may be a consequence of both the high transmission setting and the generally low socio-economic status of this community. In addition, findings from Kenya suggest that whilst asset data (as used in our wealth index) may effectively capture differences in socio-economic status at national scales, expenditure data (which was not collected) may be a more appropriate measure in rural settings [38]. Although our results do suggest that risk of infection was equal across all socio-economic groups, the least poor and most educated were still significantly more likely to own and use bed nets than their poorer and less well educated counterparts. This pro-rich bias in net ownership is similar to that found in studies conducted in comparable settings, including Tanzania [24,39], Kenya [40,41], Ghana $[42,43]$ and the Gambia [44], suggesting that the inequities estimated in this study are typical of those found in low-income settings.

Infection risk was strongly associated with proximity of households to rice-growing areas, emphasizing how this habitat may provide optimal breeding and resting sites for mosquitoes. There was however little evidence of a consistent second-order spatial pattern occurring over the entire study region as shown by variography. The relationship between malaria infection and distance from potential vector breeding sites has been reported in studies in both rural $[45,46]$ and urban communities $[36,47]$, with entomological studies suggesting that mosquitoes tend not to disperse far from breeding sites when blood meals (i.e. humans) and aquatic habitats are in close proximity [48-50]. Importantly however, whilst attention has focused on associations between rice agroecosystems, mosquito diversity and malaria transmission in Kenya and Tanzania [51-54], far less is known of the impact of this habitat type on malaria transmission in Uganda. Nonetheless, our findings are consistent with entomological studies elsewhere demonstrating the suitability of rice paddies as a larval habitat for An. gambiae, the most likely vector in this region $[52,55]$; further entomological studies are however needed to confirm this finding. Consequently, our results emphasize how an understanding of transmission heterogeneity within communities can be vastly improved by knowledge of the geographic locality of breeding sites [48].

There are a number of policy implications arising from this study. First, given the protection afforded by sleeping under a mosquito net coupled with the current low usage among school-aged children, there is a clear need to promote net use amongst school-age children. Whilst targeting individual protection to vulnerable groups is an accepted priority, recent evidence does suggest that protecting all community members can yield enhanced benefits in terms of health and social equity [56]. However, observed inequalities in ownership of bed nets across socio-economic groups in Mulanda 
suggest that, in order to dramatically increase universal coverage, the costs associated with acquiring a net must be reduced. Whilst there is debate surrounding the most appropriate approach to achieving equitable and sustainable ITN delivery [57-62], several studies have indicated that post-intervention inequalities in net use are lower following free distribution campaigns than following social marketing interventions $[40,42,43]$. Current distribution strategies in Uganda are focused on young children and pregnant women, following a mixed model that includes both the commercial sector and civil society organizations. Our findings suggest that these strategies should be extended to specifically target school children. For example, provision of free or heavily subsidized LLINs through schools and encouragement of residential (boarding) schools to provide nets in dormitories, coupled with a skills-based health education, would help to ensure that children develop the knowledge, attitudes and skills necessary to reduce their malaria risk [63].

Second, the data demonstrates a strong relationship between infection risk and proximity to rice fields, emphasizing a role for localized environmental management. There has been recent renewed interest in larval control as part of integrated malaria control strategies [64], with theoretical studies suggesting that the true effectiveness of many vector-control methods may be much greater than previously thought [65]. Encouragingly, in urban settings environmental management strategies have successfully led to reductions in adult mosquito density [66] and malaria transmission and morbidity $[67,68]$. Whilst malaria transmission in rural environments is typically less focal, our results do support previous observations that malaria risk in these communities is greatest near mosquito breeding sites $[36,47,69,70]$ suggesting that some form of targeted larval control may prove a helpful supplement to the use of insecticide-treated nets.

\section{Conclusion}

Cost-effective intervention options in malaria endemic communities need to be guided by an informed understanding of the local epidemiology of infection. These results show bed net use to be strongly associated with a decreased risk of infection in this rural Ugandan community, especially among school-aged children. Despite this, the number of individuals reporting sleeping under a bed net was inadequate, with dramatic increases in coverage required to meet current national and international targets. Findings also indicate that infection risk is influenced by proximity to potential mosquito breeding grounds, highlighting potential targets for localized environmental management. Taken together, these results underline the need for a targeted approach to integrated vector-control initiatives, further emphasizing the value of spatially explicit, community-based studies when evaluating ongoing control efforts.

\section{Additional file 1: Bivariate logistic regression models for Plasmodium spp. infection, stratified by age group. The data provided represent the preliminary statistical analysis of risk factors for Plasmodium spp. infection, for all ages and stratified by age group. Click here for file \\ [http://www.biomedcentral.com/content/supplementary/1475-2875-9-2- S1.DOC ]}

\section{Acknowledgements}

The authors are very grateful to inhabitants of Mulanda who kindly participated in the study and thank all the members of the study team in Uganda for their tireless effort and excellent work. We also thank Jon Cox for helping acquire the satellite data. RLP is supported by a Medical Research Council DTA-funded studentship, SB is supported by a Research Career Development Fellowship from the Wellcome Trust (\#081673) and RWS is a Wellcome Trust Principal Research Fellow (\#079080). The fieldwork was supported through SB's fellowship.

\section{Author details}

'Department of Infectious and Tropical Diseases, London School of Hygiene and Tropical Medicine, UK. ${ }^{2}$ Uganda Malaria Surveillance Project, Mulago Hospital, Kampala, Uganda. ${ }^{3}$ Malaria Public Health and Epidemiology Group, Kenya Medical Research Institute/Wellcome Trust Research Programme, Nairobi, Kenya. ${ }^{4}$ Centre for Tropical Medicine, Nuffield Department of Clinical Medicine, University of Oxford, Oxford, UK.

\section{Authors' contributions}

The study was designed by RLP and SB. RLP collected the data, with support from HB, SGS and SB. RWS provided scientific advice on analysis and interpretation. RLP developed the initial draft paper and all authors read, commented on and approved the final manuscript

\section{Competing interests}

The authors declare that they have no competing interests.

Received: 25 August 2009

Accepted: 4 January 2010 Published: 4 January 2010

\section{References}

1. Malaria Control Programme MoH: Uganda Malaria Control Strategic Plan 2005/06 - 2009/10

2. Snow RW, Craig M, Deichmann U, Marsh K: Estimating mortality, morbidity and disability due to malaria among Africa's non-pregnant population. Bull World Hlth Organ 1999, 77:624-640.

3. Snow RW, Marsh K: The consequences of reducing transmission of Plasmodium falciparum in Africa. Adv Parasitol 2002, 52:235-264.

4. Idro R, Aloyo J, Mayende L, Bitarakwate E, John CC, Kivumbi GW: Severe malaria in children in areas of low, moderate and high transmission intensity in Uganda. Trop Med Int Health 2006, 11:115-124.

5. Idro R, Bitarakwate E, Tumwesigye E, Chandy CJ: Clinical manifestations of severe malaria in the highlands of southwestern Uganda. Am J Trop Med Hyg 2005, 72:561-567.

6. Ndyomugyenyi R, Magnussen P: Malaria morbidity, mortality and pregnancy outcome in areas with different levels of malaria transmission in Uganda: a hospital record-based study. Trans $R$ Soc Trop Med Hyg 2001, 95:463-468.

7. Ndyomugyenyi $R$, Magnussen P: Trends in malaria-attributable morbidity and mortality among young children admitted to Ugandan hospitals, for the period 1990-2001. Ann Trop Med Parasitol 2004, 98:315-327.

8. Hay SI, Guerra CA, Gething PW, Patil AP, Tatem AJ, Noor AM, Kabaria CW, Manh BH, Elyazar IR, Brooker S, Smith DL, Moyeed RA, Snow RW: A world malaria map: Plasmodium falciparum endemicity in 2007. PLoS Med 2009, 24:e1000048. 
9. Talisuna A, Langi P, Bakyaita N, Egwang TG, Mutabingwa TK, Watkins WE, Van Marck E, D'Alessandro U: Intensity of malaria transmission, antimalarial-drug use and resistence in Uganda: what is the relationship between these three factors?. Trans R Soc Trop Med 2002, 96:310-317.

10. Okello PE, Van Bortel W, Byaruhanga AM, Correwyn A, Roelants P, Talisuna A, D'Alessandro U, Coosemans M: Variation in malaria transmission intensity in seven sites throughout Uganda. Am J Trop Med Hyg 2006, 75:219-225.

11. Uganda Bureau of Statistics U: Uganda: DHS, 2006 - Final Report Macro International Inc: Calverton, Maryland, USA 2006.

12. Filmer D, Pritchett $\mathrm{LH}$ : Estimating wealth effects without expenditure data-or tears: an application to educational enrollments in states of India. Demography 2001, 38:115-132.

13. Gilks WR, Richardson S, Spiegelhalter DJ: Markov Chain Monte Carlo in Practice London: Chapman and Hall 1996.

14. Diggle P, Moyeed R, Tawn J: Model-based geostatistics (with discussion). Applied Statistics 1998, 47:299-350.

15. Ribeiro JM, Seulu F, Abose T, Kidane G, Teklehaimanot A: Temporal and spatial distribution of anopheline mosquitos in an Ethiopian village: implications for malaria control strategies. Bull World Health Organ 1996, 74:299-305.

16. Government of Uganda: Atlas of Uganda Department of Lands and Surveys, Uganda 1962.

17. Jelliffe EFP, Jelliffe DB: Plasmodium malariae in Ugandan children. I. Prevalence in young children in rural communities. Am J Trop Med Hyg 1963, 12:296-297.

18. Onori E: Distribution of Plasmodium ovale in the eastern, western and northern regions of Uganda. Bull World Health Organ 1967, 37:665-668.

19. Onori E: Differences in Plasmodium malariae prevalence in Uganda. Bull World Health Organ 1967, 37:330-331.

20. Ministry of Health, Uganda/World Health Organisation: Annual reports of the Uganda Malaria Eradication Pilot Project 1959.

21. Francis D, Nsobya SL, Talisuna A, Yeka A, Kamya MR, Machekano R, Dokomajilar C, Rosenthal PJ, Dorsey G: Geographic differences in antimalarial drug efficacy in Uganda are explained by differences in endemicity and not by known molecular markers of drug resistance. $J$ Infect Dis 2006, 193:978-986.

22. Killeen GF, Tami A, Kihonda J, Okumu FO, Kotas ME, Grundmann H, Kasigudi N, Ngonyani H, Mayagaya V, Nathan R, Abdulla S, Charlwood JD, Smith TA, Lengeler C: Cost-sharing strategies combining targeted public subsidies with private-sector delivery achieve high bednet coverage and reduced malaria transmission in Kilombero Valley, southern Tanzania. BMC Infect Dis 2007, 7:121.

23. Bernard J, Mtove G, Mandike R, Mtei F, Maxwell C, Reyburn H: Equity and coverage of insecticide-treated bed nets in an area of intense transmission of Plasmodium falciparum in Tanzania. Malar J 2009, 8:65.

24. Matovu F, Goodman C, Wiseman V, Mwengee W: How equitable is bed net ownership and utilisation in Tanzania? A practical application of the principles of horizontal and vertical equity. Malar J 2009, 8:109.

25. Noor AM, Moloney G, Borle M, Fegan GW, Shewchuk T, Snow RW: The use of mosquito nets and the prevalence of Plasmodium falciparum infection in rural South Central Somalia. PLOS ONE 2008, 3:e2081.

26. Shargie EB, Gebre T, Ngondi J, Graves PM, Mosher AW, Emerson PM, Ejigsemahu Y, Endeshaw T, Olana D, WeldeMeskel A, Teferra A, Tadesse Z, Tilahun A, Yohannes G, Richards FO: Malaria prevalence and mosquito net coverage in Oromia and SNNPR regions of Ethiopia. BMC Public Health 2008, 21:321.

27. Afolabi BM, Sofola OT, Fatunmbi BS, Komakech W, Okah F, Saliu O, Otesemobor P, Oresanya OB, Amajoh CN, Fasiku D, Jalingo I: Household possession, use and non-use of treated or untreated mosquito nets in two ecologically diverse regions of Nigeria-Niger Delta and Sahel Savannah. Malar J 2009, 8:30.

28. Noor AM, Kirui VC, Brooker S, Snow RW: The use of insecticide treated nets by age: implications for universal coverage in Africa. BMC Public Health 2009, 9:369.

29. Clarke S, Bogh C, Brown R, Pinder M, Walraven G, Lindsay SW: Do untreated bednets protect against malaria?. Trans R Soc Trop Med 2001, 95:457-462.
30. Guyatt H, Corlett S, Robinson T, Ochola SA, Snow RW: Malaria prevention in highland Kenya: indoor residual house-spraying vs. insecticide-treated bednets. Trop Med Int Health 2002, 7:298-303.

31. Lengeler $C$ : Insecticide-treated bed nets and curtains for preventing malaria. Cochrane Database Syst Rev 2004, CD000363.

32. Mboera LE, Kamugisha ML, Rumisha SF, Kisinza WN, Senkoro KP, Kitua AY: Malaria and mosquito net utilisation among schoolchildren in villages with or without healthcare facilities at different altitudes in Iringa District, Tanzania. Afr Health Sci 2008, 8:114-119.

33. Gamage-Mendis AC, Carter R, Mendis C, De Zoysa AP, Herath PR, Mendis KN: Clustering of malaria infections within an endemic population: risk of malaria associated with the type of housing construction. Am J Trop Med Hyg 1991, 45:77-85.

34. Koram KA, Bennett $\mathrm{S}$, Adiamah $\mathrm{JH}$ : Socio-economic risk factors for malaria in a peri-urban area of The Gambia. Trans $R$ Soc Trop Med 1995, 89:146150.

35. Graves PM, Richards FO, Ngondi J, Emerson PM, Shargie EB, Endeshaw T, Ceccato $P$, Ejigsemahu $Y$, Mosher AW, Hailemariam A, Zerihun M, Teferi T, Ayele B, Mesele A, Yohannes G, Tilahun A, Gebre T: Individual, household and environmental risk factors for malaria infection in Amhara, Oromia and SNNP regions of Ethiopia. Trans $R$ Soc Trop Med 2009, 103:1211-1220.

36. Matthys B, Vounatsou P, Raso G, Tschannen AB, Becket EG, Gosoniu L, Cisse B, Tanner M, N'Goran EK, Utzinger J: Urban farming and malaria risk factors in a medium-sized town in Cote d'Ivoire. Am J Trop Med Hyg 2006, 75:1223-1231.

37. Snow RW, Peshu N, Forster D, Bomu G, Mitsanze E, Ngumbao E, Chisengwa R, Schellenberg JR, Hayes RJ, Newbold Cl, Marsh K: Environmental and entomological risk factors for the development of clinical malaria among children on the Kenyan coast. Trans $R$ Soc Trop Med Hyg 1998, 92:381-385.

38. Chuma J, Molyneux CS: Estimating inequalities in ownership of insecticide treated nets: does the choice of socio-economic status measure matter?. Health Policy Plan 2009, 24:83-93.

39. Mushi AK, Schellenberg JR, Mponda H, Lengeler C: Targeted subsidy for malaria control with treated nets using a discounted voucher system in Tanzania. Health Policy Plan 2003, 18:163-171.

40. Noor AM, Amin AA, Akhwale WS, Snow RW: Increasing coverage and decreasing inequity in insecticide-treated bed net use among rural Kenyan children. PLoS Med 2007, 4:e255.

41. Noor AM, Omumbo JA, Amin AA, Zurovac D, Snow RW: Wealth, mother's education and physical access as determinants of retail sector net use in rural Kenya. Malar J 2006, 5:5.

42. Grabowsky M, Nobiya T, Ahun M, Donna R, Lengor M, Zimmerman D, Hoekstra E, Bello-Wilmot A, Amofah G: Distributing insecticide-treated bednets during measles vaccination: a low cost means of achieving high and equitable coverage. Bull World Health Organ 2005, 83:3.

43. Grabowsky M, Farrell N, Hawley WA, Chimumbwa J, Hoyer S, Wolkon A, Selanikio J: Integrating insecticide-treated bednets into a measles vaccination campaign achieves high, rapid and equitable coverage iwth direct and voucher based methods. Trop Med Int Health 2005, 10:11511160 .

44. Wiseman V, McElroy B, Conteh L, Stevens W: Malaria prevention in the Gambia: patterns of expenditure and determinants of demand at the household level. Trop Med Int Health 2006, 11:419-431.

45. Peterson E, Borrel LN, El-Sard W, Teklehaimanot A: Individual and household level factors associated with malaria incidence in a highland region of Ethiopia: a multilevel analysis. Am J Trop Med Hyg 2009, 80:103111.

46. Clarke SE, Bogh C, Brown RC, Walraven GE, Thomas CJ, Lindsay SW: Risk of malaria attacks in Gambian children is greater away from malaria vector breeding sites. Trans R Soc Trop Med 2002, 96:499-506.

47. Staedke SG, Nottingham EW, Cox J, Kamya MR, Rosenthal PJ, G D: Short report: proximity to mosquito breeding sites as a risk factor for clinical malaria episodes in an urban cohort of Ugandan children. Am J Trop Med Hyg 2003, 69:244-246.

48. Machault V, Gadiaga L, Vignolles C, Jarjaval F, Bouzid S, Sokhna C, Lacaux JP, Trape JF, Rogier C, Pages F: Highly focused anopheline breeding sites and malaria transmission in Dakar. Malar J 2009, 8:138. 
49. Minakawa N, Seda P, Yan G: The influence of host and larval habitat distribution on the adundance of African malaria vectors in Western Kenya. Am J Trop Med Hyg 2002, 67:32-38.

50. Trape JF, Lefebvre-Zante $E$, Legros F, Ndiaye $G$, Bouganali $H$, Druilhe $P$, Salem G: Vector density gradients and the epidemiology of urban malaria in Dakar, Senegal. Am J Trop Med Hyg 1992, 47:181-189.

51. Muturi EJ, Shililu J, Jacob BG, Mwangangi J, Mbogo C, Githure J, Novak RJ: Diversity of riceland mosquitoes and factors affecting their occurrence and distribution in Mwea, Kenya. J Am Mosa Control Assoc 2008, 24:349358.

52. Muturi EJ, Muriu S, Shililu J, Mwangangi J, Jacob BG, Mbogo C, Githure J, Novak RJ: Effect of rice cultivation on malaria transmission in central Kenya. Am J Trop Med Hyg 2008, 78:270-275.

53. Ijumba JN, Shenton FC, Clarke SE, Mosha FW, Lindsay SW: Irrigated crop production is associated with less malaria than traditional agriculture practices in Tanzania. Trans $R$ Soc Trop Med 2002, 96:476-480.

54. Ng'ang'a ZW, Shililu J, Jayasinghe G, Kimani V, Kabutha C, Kabuage L, Githure J, Mutero C: Malaria vector control practices in an irrigated rice agro-ecosystem in central kenya and implications for malaria control. Malar J 2008, 7:146.

55. Diuk-Wasser MA, Touré MB, Dolo G, Bagayoko M, Sogoba N, Sissoko I, Traoré SF, Taylor CE: Effect of rice cultivation patterns on malaria vector abundance in rice-growing villages in Mali. Am J Trop Med Hyg 2007, 76:869-874.

56. Killeen GF, Smith TA, Ferguson HM, Mshinda H, Abdulla S, Lengeler C, Kachur SP: Preventing childhood malaria in Africa by protecting adults from mosquitoes with insecticide-treated nets. PLoS Med 2007, 4:e229.

57. Nathan R, Masanja H, Mshinda H, Schellenberg JA, De Savigny D, Lengeler C, Tanner M, Victoria CG: Mosquito nets and the poor: can social marketing redress inequalities in access?. Trop Med Int Health 2004, 9:1121-1126.

58. England R: Towards sustainable malaria control. Lancet 2007, 370:1864

59. Skarbinski J, Massaga JJ, Rowe AK, Kachur SP: Distribution of free, untreated bednets bundled with insecticide via an integrated child health campaign in Lindi region, Tanzania: lessons for future campaigns. Am J Trop Med Hyg 2007, 76:1100-1106.

60. Teklehaimanot A, Sachs JD, Curtis C: Malaria control needs mass distribution of insecticidal bednets. Lancet 2007, 369:2143-2146.

61. Khatib RA, Killeen GF, Abdulla S, Kahigwa E, McElroy PD, Gerrets RPM, Mshinda H, Mwita A, Kachur SP: Markets, voucher subsidies and free nets combine to achieve high bednet coverage in rural Tanzania. Malar $J$ 2008, 7:98.

62. Pettifor A, Taylor E, Nku D, Duvall S, Tabala M, Mwandagalirwa K, Meshnick S, Behets F: Free distribution of insecticide treated bed nets to pregnant women in Kinshasa: an effective way to achieve $80 \%$ use by women and their newborns. Trop Med Int Health 2009, 9:1121-1126.

63. Brooker S, Clarke S, Snow RW, Bundy DAP: Malaria in African schoolchildren: options for control. Trans R Soc Trop Med 2008, 102:304305.

64. Walker K, Lynch M: Contributions of Anopheles larval control to malaria suppression in tropical Africa: review of achievements and potential. Med Vet Entomol 2007, 21:2-21.

65. Killeen GF, Knols BG, Gu W: Taking malaria tranmission out of the bottle: implications of mosquito dispersal for vector-control interventions. Lancet Infect Dis 2003, 3:297-303.

66. Yohannes M, Haile M, Ghebreyesus TA, Witten KH, Getachew A, Byass P, Lindsay S: Can source reduction of mosquito larval habitat reduce malaria transmission in Tigray, Ethiopia?. 2005, 10:1274-1285.

67. Geissbühler Y, Kannady K, Chaki PP, Emidi B, Govella NJ, Mayagaya V, Kiama M, Mtasiwa D, Mshinda H, Lindsay S, Tanner M, Fillinger U, de Castro MC, Killeen GF: Microbial larvicide application by a large-scale, community-based program reduces malaria infection prevalence in urban Dar es Salaam, Tanzania. PLoS ONE 2009, 4:e5107.

68. Fillinger U, Kannady K, William G, Vanek MJ, Dongus S, Nyika D, Geissbühler Y, Chaki PP, Govella NJ, Mathenge EM, Singer BH, Mshinda H, Lindsay SW, Tanner M, Mtasiwa D, de Castro MC, Killeen GF: A tool box for operational mosquito larval control: preliminary results and early lessons from the Urban Malaria Control Programme in Dar es Salaam, Tanzania. Malar J 2008, 7:20
69. Lautze J, McCartney M, Kirshen P, Olana D, Jayasinghe G, Spielman A: Effect of a large dam on malaria risk: the Koka reservoir in Ethiopia. Trop Med Int Health 2007, 12:982-989.

70. Ghebreyesus TA, Haile M, Witten KH, Getachew A, Yohannes AM, Yohannes M, Teklehaimanot HD, Lindsay SW, Byass P: Incidence of malaria among children living near dams in northern Ethiopia: community based incidence survey. BMJ 1999, 319:663-666.

doi:10.1186/1475-2875-9-2

Cite this article as: Pullan et al:: Plasmodium infection and its risk factors in eastern Uganda. Malaria Journal 2010 9:2.

\section{Publish with Bio Med Central and every scientist can read your work free of charge}

"BioMed Central will be the most significant development for disseminating the results of biomedical research in our lifetime. "

Sir Paul Nurse, Cancer Research UK

Your research papers will be:

- available free of charge to the entire biomedical community

- peer reviewed and published immediately upon acceptance

- cited in PubMed and archived on PubMed Central

- yours - you keep the copyright
BioMedcentral 